\title{
Ocorrência de Aspergillus Seção Nigri Isolados de Uvas Passas
}

Camila Alvarenga Freire (I), Luisa Freire (I), Nathasha De Azevedo Lira (I), Fabiana Reinis Franca Passamani (I), Luis Roberto Batista

(I) UFLA - Universidade Federal de Lavras (Câmpus Universitário, Caixa Postal 3037, CEP 37200-000, Lavras/MG)

\section{Resumo}

As frutas secas, como as uvas-passa, são produtos naturais e apresentam alto teor de açúcar e uma baixa atividade de água, favorecendo o crescimento de fungos xerofílicos e xerotolerantes produtores de micotoxinas. Neste sentido, o presente estudo teve como objetivo identificar fungos pertencentes à seção Nigri isolados de uvas passas comercializadas no município de Lavras - MG. A pesquisa foi desenvolvida no Laboratório de Micologia de Alimentos - Departamento de Ciência dos Alimentos - DCA/ UFLA. Foram analisadas dez amostras utilizando a técnica de plaqueamento direto, com desinfecção superficial, em meio de cultura DRBC, por 7 dias, a $25^{\circ} \mathrm{C}$. Após este período, os isolados foram purificados em meio de cultura MA a $25^{\circ} \mathrm{C}$ por 7 dias. As culturas puras foram transferidas para os meios de identificação padronizados, CYA a $25^{\circ} \mathrm{C}$ e $37^{\circ} \mathrm{C}$ e MEA a $25^{\circ} \mathrm{C}$ por 7 dias. A identificação foi realizada através das características macro e microscópicas de acordo com manuais de identificação. Todas as amostras analisadas apresentaram contaminação com fungos filamentosos. Os níveis de contaminação variaram de 5\% a 100\%.Foram identificados, até o momento, 83 fungos pertencentes à seção Nigri: A.carbonarius (8), A.foetidus (10), A. aculeatus (1), A.niger Agregado (4), A.tubingensis (23), A. niger (36) e A. japonicus (1). A incidência de fungos Aspergillus Seção Nigri potencialmente ocratoxigênicos, A. niger e A. carbonarius é 
considerado um risco potencial de contaminação por ocratoxina A, comprometendo a segurança e qualidade das uvas passas. Estes resultados demonstram a necessidade de adoção de critérios de seleção das uvas passas e um controle efetivo no armazenamento, para evitar o desenvolvimento dos fungos potencialmente toxigênicos, mantendo a qualidade do produto e a proteção da saúde do consumidor, reduzindo a exposição à micotoxinas.

Palavras-Chave: Uvas passas, Aspergillus, Fungos filamentosos Agência de Fomento: Cnpq, Fapemig 